LIBRES: Library and Information Science Research

Electronic Journal ISSN 1058-6768

1997 Volume 7 Issue 2; September 30.

Bi-annual LIBRE7N2

\title{
Information Infrastructure in Hungary: How Academic Libraries use it
}

\author{
Tibor Koltay Central Library, Godollo University of Agricultural Sciences, Hungary \\ Tibor@KPKO.GAU.HU \\ Geza Bakonyi Central Library, Jozsef Attila University, Hungary \\ Laszlo Drotos, Central Library, University of Miskolc, Hungary
}

This article describes achievements in Hungarian networking and fields of networking activities.

Examples of the use of networking infrastructure are taken from three academic libraries.

\section{Introduction}

Academic libraries have to struggle with a number of problems. Their situation has to be seen in the light of the development of the higher education system in Hungary. On the one hand this system is characterized by fragmentation. This means that there are not only universities with several and diverse faculties, but there is a number of "specialized" universities often serving a relatively low number of students. On the other hand most universities and their libraries have to count with growing numbers of students without being able to expand facilities and the number of staff. The latter has been diminishing because of government downswing measures.

Various studies conducted by Hungarian teams of librarians and by external consultants confirm the widely recognized fact, that the changes in Hungarian higher education will require enhanced funding and significant improvements in university and college libraries the means for which are only partially available. Despite problems academic libraries have been able to take advantage of the existing infrastructure and many of them are in the forefront of networking.

Achievements in networking depend very much on the good attitude of individual staff members and the understanding of its importance by senior management that allow these individuals to engage in a number of activities. Institutional framework for networking on the national level is provided by the HUNGARNET Association that comprises all 
academic, research and non-profit public sites whose number is over 850 .

Traditions in Hungarian networking are especially due to the activities of a national institution closely related to HUNGARNET. It is the National Information Infrastructure Development Programme (NIIF) established in 1997. NIIF initiated the establishment and has been supporting the use of an X.25 network and it ensures full Internet connectivity.

\section{The infrastructure}

Internal connectivity of HUNGARNET is based partly on the public X.25 service of the Hungarian PTT and partly on the community's private IP backbone network (HBONE). The kernel of the HBONE infrastructure is in Budapest, where several important organizations are connected in different ways. Several cities (regional centers) in the country are also connected to the network. In an ongoing development new regional centers and several other organizations will be connected subsequently. The number of Internet hosts was around 17000 in 1996 . With the support of the NIIF 150 databases and several hundreds of WWW sites and Gopher servers have been set up in Hungary.

\section{Networking activities}

The use of e-mail is widespread. The number of mailboxes in the academic sector reached 15.000 (1). A growing number of libraries use e-mail for forwarding interlibrary loan request to other Hungarian libraries. There are more than 40 electronic discussion fora in Hungarian language. Many of them deal with problems related to networking. The latter often appeared by the initiative of academic libraries and librarians that take active part in their work.

Among fora on networking the first, and for a long time unique forum has been KATALIST. This popular forum deals with almost all aspects of library automation and networking and its scope is not restricted to libraries. From this forum new lists branched out, which show more specialized profiles.

MEK-L deals with the problems of the Hungarian Electronic Library. WWW-L is dedicated to the problems of building WWW servers respectively.

There are discussion groups related to integrated library systems, as well. Two of the systems used in many Hungarian academic libraries TinLIB and ALEPH maintain listservers. A considerable amount of Hungarian language fora is maintained by Hungarian Americans and these fora are run on computers in the United States.

An important initiative by academic librarians is the Hungarian Electronic Library (MEK). For a nation, that speaks a language that does not belong to world languages, but has a rich tradition in literature the thought of a text-archive has special importance. Probably, this also contributed to the fact that the thought of the Hungarian Electronic Library was raised very early. However, not only literature can be found in this archive but those of the various areas of sciences and social sciences, too. This is a central service, that is accessible through one of the computers of the NIIF. 
The Hungarian Electronic Library, archives both belles-letters and scientific texts in Hungarian and/or related to Hungary and Central Europe. MEK is meant to be a real library that is not only an archive but a cataloged library that uses a short, tagged MARC-like cataloging format. One of the problems related to the maintenance of this library is the use of the Hungarian character set. At present several protocols are used depending on the type of the computer and on the network environment of the users. Unfortunately, the general use of the common protocol (ISO 8859-2) is going forward slowly. The education of a wide range of users is regarded as an important activity. In this process academic libraries play a special role.

Beside other forms of user education a series of printed Hungarian-language guides on different aspects of networking is in preparation as a project of the NIIF. It is not surprising that many academic libraries are participating in this project. These guides can be divided roughly into two groups: the "How to use..." and the "How to build your own..." type. Topics include the use of e-mail, telnet, ftp. The booklets deal with the virtual world of the Net, its use in libraries and in schools. There will be a guide on using gopher as a tool of searching for information, and another one on making someone's own gopher server. Similarly, you will learn how to build an anonymous ftp server.

The "how to use" series again has two branches. One of them explains the tools, while the booklets of the second branch will introduce to sources of different fields. The topics of the already published booklets are the following:

\section{Series 1}

Are you on the Net?

Using e-mail on the Internet

Searching online library catalogs

Living in the virtual world of the Net

Using the Net for research

astronomy and space research

computer graphics

history

environmental sciences

microbiology

Using the Net in schools

Using the Net with Windows

Using the Net with modem

Searching the Net for information

Series 2

How to build your own Gopher?

How to run your own Bitnet/Internet discussion group?

How to defend your system on the Net?

How to make your own homepage?

How to use the Internet on a Linux system? 
Networking dictionary

A number of booklets appeared already in print form and even more exist in electronic form and wait for printing, since all guides will exist in this duplicated form. Many of the are already available in html-format. All available documents can be downloaded from NIIF's WWW server. At present over 30 library OPACs are accessible via Telnet. Though more and more libraries purchase integrated library systems, current cataloging and retrospective conversion are slow especially because of the lack of shared cataloging systems. Practically all Hungarian universities and most cities with important colleges have at least a gopher site and/or a WWW node and there is a number of anonymous FTP servers.

NIIF supports the development of tools that enable direct WWW access to OPACs. This direct access means an easy to use interface that eliminates the necessity to telnet to different computers and does not require any knowledge of the different search systems of these OPACs.

Shared cataloging, lacking until recently, gained momentum in Hungary with recent initiative of 15 libraries that would hopefully cover the still existing gap in this important field. The project involves libraries of all types of importance. The participants won support of a number of foundations and the Ministry of Culture and Education to acquire software for shared cataloging to be run on NIIF's computer and to begin with filling up the system. NIIF has recently announced a project, which will foster teleworking of scientists. This program will allow them to get free or low-priced telecommunication software and reach an Internet gateway with their modems, while paying a small membership fee and the costs of local telephone calls.

\section{How academic libraries use the infrastructure}

The overview above has shown, that Hungarian academic libraries, especially those at larger (even though sizes are small compared to those in other larger than Hungary countries) universities are often in the forefront of networking. Although different in size and profile, these libraries pay much attention to networking. The examples below do not provide a complete picture of a colorful range of possibilities and activities, but are intended to illustrate this variety. Undoubtedly these libraries show a number of characteristics that can be found in other academic libraries, as well.

One of the similarities among all three libraries described below is that their staff plays an active role in networking. Many of them are (co)authors of networking guides already appeared or are in preparation.

\section{Central Library of Jozsef Attila University, Szeged}

The library was an early starter in using computers and networks often under improper conditions for an adequate application of the modern information technology. Experiences in the past nonetheless made many librarians to understand now, that materials already 
processed in one way have to be converted into newly developed and purchased means. Lessons from the past remind us that the developments of the libraries have to be attached not to hardware and software but to services and expected needs of users.

Cooperating with the Computer Center of the University, the automated book processing began in 1977 and in the second half of the 80s other special databases were created. Later both the OPAC and the other databases are converted and could be used with BRS/Search. As a result of the early beginning and the good networking attitude of many staff members, the library's staff obtained a considerable experience first of all in automation. This will probably be a great help by installing the library's new Voyager integrated system, chosen from commercially available systems available in Hungary.

Within a relatively short period a good Web server could be established (the WWW OPAC of the library is the second in its type in the country). Beside the usual options (local services, links, virtual library) an electronic library has been elaborated. This intends to collect literary works related to the city of Szeged, but which have national importance, as well. The library made an attempt to process, digitalize the basic materials of the university instruction, within that especially those used in the instruction of Hungarian history. Within the Web and with the help of the BRS/Search a local history database has been established, the material of which is supplied by ten large public libraries of the Eastern part of the Hungarian Plains.

Significant part of the Web server is occupied by the pages of virtual exhibitions. In addition to this the Web site provides information among others about the American Higher Education Information Center and the special collections (Old books and manuscripts, the "Lajos Ligeti" Oriental Collection, the collection on military history). Personal homepages of staff members are available. The library's homepage won second prize of the Hungarian WWW "beauty contest" in 1996. Direct Web searching interface is available to the university library OPAC.

The way towards the future development is envisaged by the library in similar integrated projects. There is a joint library system and a union catalogue with five other libraries in preparation. In the near future a project will begin to develop a common user interface together with three or four university libraries.

\section{Central Library of Godollo University of Agricultural Sciences, Godollo}

In the library developments in automation and networking have begun with the general computerization at the university itself. As it often happened in other libraries, automation began with the acquisition of a turnkey system. Full Internet access is provided.

Nonetheless students cannot access the Net from the library, but from the departments.

Networking activity in the library is among librarians, especially in the field of reference. All professionals in the library have at least basic training in networking. Those who did not subscribe to any of the discussion fora still have the possibility to get informed, as the 
Notice board function of the library's Pegasus Mail (on the Novell LAN) is used to collect and display the most important messages of several Hungarian discussion fora on different aspects of networking.

At the university there is a number of WWW servers. One of these is the Central Library's server. It contains detailed information about the services and the use of the library and makes the list of newest acquisitions available. Links are provided to the other WWW servers of the University (and vice versa). Visitors to this Web site can get acquainted with library's staff. Similarly to the majority of Hungarian Web servers this pages offer a bilingual (Hungarian-English) access, even though the Hungarian pages are more extensive.

A unique feature of the library homepage is that the development of the faculties and other units of the university is illustrated here as a html document. This is part of the 75 anniversary exhibition of the establishment of the university and exist as an exhibit only in this form (unfortunately only in Hungarian). Where possible, links are provided to the actual page describing the structure of the given unit and users can jump from the upper overview-page to more detailed descriptions of the developments. The library's TinLIB OPAC is accessible on the Internet.

\section{Central Library of the University of Miskolc, Miskolc}

This library was one of the first libraries in the country that gave access to its patrons to the world's largest online database services in the eighties. The usage of these commercial online services diminished in the recent years due to the appearance of CD-ROMs and the use of the Internet.

The library participates in a project to build a wide area CD-ROM network in cooperation with the university libraries of Debrecen and Kosice (Slovakia).

Beside the University's gopher and WWW server the Library's own monthly newsletter: Online Hirado ("Online News") has to be mentioned. This was the first regularly published Hungarian newsletter about the online information sources (first about the commercial database providers, then about foreign Internet services, and nowadays mostly about the new Hungarian online developments). The Online Hirado appears in printed and in electronic (ASCII) form, and now there is a WWW version as well. There is a number of educational and informative material written or translated in the Library's staff and circulated on various Hungarian servers.

Miskolc was the birth place of the idea of the Hungarian Electronic Library and for a year the university's gopher was one of the test site of this electronic text archive.

The library automation was stand-alone PC-based in the past. The installation of the new integrated library software (Dynix Horizon) is just started. Until the development of a full-functioning OPAC, the Library offers two Oracle databases (recently acquired books and current periodicals) over the Internet. The public Internet terminals are very popular 
among patrons.

\section{References}

The National Information Infrastructure for Research, Development Higher Education, Public Libraries and Public Collections in Hungary. An Overview of Computer Networking and Information Services in the Academic and R\&D Community of Hungary. Prepared by the NIIFP Coordination Centre and the HUNGARNET Association, April 1996. (http:www.iif.hu/dokumentumok/niifp9606/niif.html)

\section{Appendix}

Some Internet addresses

The Hungarian Homepage:

http://www.fsz.bme.hu/hungary/homepage.html

NIIF

http://www.iif.hu

Hungarian Electronic Library

http://www.mek.iif.hu

Godollo University of Agricultural Sciences, Central Library

http://dis.gau.hu

József Attila University, Central Library

http://www.bibl.u-szeged.hu

This document may be circulated freely

with the following statement included in its entirety:

Copyright 1997.

This article was originally published in _LIBRES: Library and Information Science

Electronic Journal_(ISSN 1058-6768) September 30, 1997

Volume 7 Issue 2.

For any commercial use, or publication

(including electronic journals), you must obtain

the permission of the authors.

Tibor Koltay Central Library, Godollo University of Agricultural Sciences, Hungary

Geza Bakonyi Central Library, Jozsef Attila University, Hungary

Laszlo Drotos, Central Library, University of Miskolc, Hungary

To subscribe to LIBRES send e-mail message to 
listproc@info.curtin.edu.au

with the text:

subscribe libres [your first name] [your last name]

Return to Libre $7 \mathrm{n} 2$ Contents

Return to Libres Home Page

CRICOS provider code: 00301J 